Логинов Е. В. Пирс и парадокс лжеца // Философия. Журнал Высшей школы экономики. -2017 . - Т. І, № 4. - С. 59-83.

\title{
ЕвГЕний Логинов*
}

\section{ПИРС И ПАРААОКС ЛЖЕЦА**}

Аннотация: Парадокс лжеца - известный самой широкой публике логический и философский парадокс, а также серьезная проблема для профессиональных философов, сыгравшая важную роль в истории философии, логики и даже математики. Я рассматриваю разные подходы к этой проблеме, предложенные американским философом и основателем прагматизма Чарльзом Сандерсом Пирсом, и пытаюсь воссоздать эволюцию его взглядов на этот вопрос. Мы можем исследовать предложение «это предложение неистинно» с трех точек зрения: его значения, его истинности и его значимости. Самый ранний подход Пирса сосредоточен на значении и истинности. Он утверждает, что суждение «это суждение неистинно» бессмысленно и вместе с тем одновременно истинно и неистинно. Он предлагает этот способ рассуждения в 1865 г. в гарвардских лекциях о логике науки. Его второй подход был представлен в статье «Основания силы законов логики: дальнейшие следствия четырех неспособностей», опубликованной в 1869 г. В этой работе Пирс отказался от своего предыдущего подхода и, сфокусировавшись лишь на истинности «лжеца», основал новое решение этого парадокса на утверждении схоластического философа Павла Венецианского: каждое суждение подразумевает утверждение собственной истинности. Тогда суждение «это суждение неистинно» подразумевает утверждение собственной истинности и в то же время говорит, что оно ложно; ergo оно ложно, поскольку оно самопротиворечиво. В 1903 г. Пирс отвергает этот подход, потому что для любого суждения верно, что оно не является эквивалентным суждению «я утверждаю это суждение». Пирс никогда не представлял третьего решения парадокса лжеца, но есть три проблемы, тесно связанные с нашей темой: связь Пирса с Бертраном Расселом, зрелая теория истины Пирса, открывающая перспективу рассмотрения «лжеца» с точки зрения значимости, и разработка Пирсом трехзначной логики. Я обсуждаю их во второй части статьи.

Ключевые слова: Пирс, Рассел, парадокс лжеца, континуум, трехзначная логика, истина.

Философы занимаются поиском истины и на своем пути постоянно встречают разного рода затруднения. Самые существенные для мысли затруднения мы называем парадоксами. Кого-то парадоксы погружают в меланхолию (Юм, Церетели, 2009: 358-370), кого-то пробуждают от догматического сна (Кант, Соловьев, 1994: 99-10о). И один парадокс касается не просто пути к истине, а самой истины. Этот парадокс хорошо известен: если некий патологический лжец говорит «я лгу», то

*Логинов Евгений Владимирович, к. филос. н., младший научный сотрудник Аналитической службы МГУ им. М. В. Ломоносова, loginovlosmar@gmail.com.

** (C) Логинов, Е. В. (C) Философия. Журнал Высшей школы экономики. 
он лжет; стало быть, он не лжет, а говорит правду; но если он говорит правду, значит он действительно лжет. Иными словами: если суждение «это суждение ложно» истинно, то оно ложно, а если оно ложно, то оно истинно. Это, как метко заметил Питер Гич, «игра, в которой невозможно сделать ни один [курсив Гича. - E. Л.] разрешенный ход» (Geach, 1954: 71). Мы можем исследовать рассматриваемое суждение в отношении трех параметров: его осмысленности (и, соответственно, можем считать его либо осмысленным, либо бессмысленным, либо и тем, и другим, либо ни тем, ни другим), его истинности (оно может принимать значения либо «истина», либо «ложь», либо «истина и ложь», либо «ни истина, ни ложь») и его значимости ${ }^{1}$ (оно, соответственно, может быть либо значимым, либо незначимым, либо и тем, и другим, либо ни тем, ни другим). Некоторые варианты prima facie кажутся менее перспективными, чем другие.

Диоген Лаэртский называет автором этого парадокса Евбулида Милетского (Диоген Лаэртский, Гаспаров, 1979: 138)², но такая атрибуция вряд ли может считаться надежной. Однако ясно, что уже у греков появилось название, которое используется и сегодня: «парадокс лжеца». Это, возможно, самый знаменитый из семейства философских парадоксов. В Средние века парадокс лжеца относили к числу т. н. insolubilia, неразрешимых, и всячески старались разрешить ${ }^{3}$. В Новое время интерес к нему несколько снизился, но логическая революция второй половины ХІх в. дала импульс новым исследованиям этой проблемы. В это время «лжец» тесно сплетается с сюжетами, связанными с теорией множеств и основаниями математики. Широко известна роль, которую сыграл схожий с парадоксом лжеца парадокс Рассела в истории ранней

${ }^{1}$ Я различаю осмысленность и значимость примерно для того же, для чего Витгенштейн в «Трактате» различает sinnlos и unsinnig,- чтобы можно было сказать, что нечто является бессмысленным, но не бесполезным. Похожее различие проводит Рассел в беседе с о. Ф. Коплстоном (Рассел, Яковлев, 2016: 252). О трудностях в определении понятия «значение» см. также: Логинов, 2016.

${ }^{2}$ Роль Эпименида, если судить по приводимым Иеронимом отрывкам, свелась к тому, что благодаря ему «лжец» обрел место жительства, а именно Крит, откуда происходил и сам поэт. В открытии логического парадокса, таким образом, Эпименид не виноват. См.: Фрагменты..., Лебедев, 1989: 77. Сюжет, связанный с ложью, Критом и Эпименидом, герой этой статьи рассматривает вне контекста парадокса лжеца, беря его в качестве примера проблематичности синтетического вывода, а именно перехода от того, что Эпименид и другие известные критяне были лжецами, к тому, что многие критянелжецы (W3: 303).

${ }^{3}$ Cм. например: Брадвардин и др., 2014; De Rijk, 1966. 
аналитической философии (Heijenoort, 1967: 124-128; Frege, Geach, 1960; Soames, 2003: 140-157; Soames, 2014: 120-129). С тех пор логики, философы языка и эпистемологи предложили немало интересных подходов к решению этой проблемы (Тарский, Никифоров, 1998: 98-103; Fraassen, 1968; Kripke, 1975; Parsons, 1984; Priest, 1984; Yablo, 1993).

Данная статья посвящена взглядам Чарльза Сандерса Пирса на этот вопрос. Если софокловски трагический анализ этого парадокса в ранней аналитической философии хорошо известен, давно опубликованы релевантные первоисточники, проведены тщательные исследования - как логические, так и историко-философские, - а знание об этом вошло в $m i$ nimum minimorum знаний по аналитической философии и философии математики, то анализ, проведенный Пирсом, известен куда меньше. До недавнего времени в отечественной литературе философия Пирса чаще всего описывалась в ее отношении к прагматическому движению, а логическая сторона творчества этого мыслителя оставалась в тени. Некоторое пренебрежение наблюдалось и в отношении ранних и поздних идей Пирса. Сегодня, к счастью, ситуация начинает меняться. Внешняя цель этой статьи состоит в поддержке этих перемен. Внутренней целью является рассмотрение эволюции взглядов Пирса на парадокс лжеца.

Было бы неверно утверждать, что для мира идей Пирса тема парадокса лжеца является центральной: многие классические пирсоведческие работы обходят этот сюжет стороной ${ }^{4}$. Но уже при самом поверхностном рассмотрении вопроса обнаруживается, что парадокс лжеца интересовал Пирса на протяжении почти всего его творчества. При более глубоком анализе может оказаться, что эта тема была связана с важнейшими сюжетами как ранней, так и зрелой философии Пирса, что было бы дополнительным свидетельством в пользу подлинно систематического характера его наследия (Myrvold, 1995: 508). Я рассмотрю два предложенных Пирсом способа решения парадокса лжеца, а потом обращусь к идеям Пирса начала Xх в., чтобы посмотреть, какие из них могли бы послужить материалом для новых подходов к этому парадоксу, а также укажу, в какой точке кривая пирсовских рассуждений о парадоксе лжеца пересекается с линией логических исследований раннего Рассела,

${ }^{4}$ См. например: Мельвиль, 1968; Ayer, 1968; Brady, 2000; Hookway, 200o; Short, 2007. 
завершившихся созданием (в соавторстве с А. Уайтхедом) «Principia Mathematica».

\section{РЕШЕНИЕ 1865 ГОДА}

Впервые к парадоксу лжеца Пирс обращается в первой и третьей лекциях из цикла лекций по логике науки, прочитанных весной 1865 г. в Гарварде. В первой лекции он обсуждает вопрос о суждении «это самое суждение ложно» (this very proposition is false), а в третьей его интересует суждение «то, что тут написано, неистинно» (what is here written is not true).

Первая лекция посвящена прежде всего поиску предмета логики и в связи с этим проблеме психологизма и антипсихологизма, которая решается с кантовских позиций, а также критике миллевского понимания логики. Пирс рассуждает так, что воспитанному в традиции аналитической философии человеку легко может показаться, что он читает не рукопись Пирса, а «Мысль» Готлоба Фреге (Фреге, Суровцев, 2008: 28-54): в частности, упоминается третий мир, мир логоса. Пирс отмежевывается от Гегеля, говоря, что логика есть не наука чистой идеи, но наука законов опыта, существующих в силу его, опыта, определенности идеей. В этом смысле логика-это формальная наука, которая занимается репрезентациями мира. Репрезентации бывают трех видов: копии, знаки и символы. Это деление примерно соответствует известному 5 и более позднему пирсовскому делению на иконы, индексы и символы: копии имеют реальное сходством с тем, что они репрезентируют, знаки существуют за счет конвенций, а символы связаны с объектами отношением референции. Логика не изучает физические сходства и конвенции, поэтому ее предмет-символы. «Законы логики истинны относительно всех символов» (W1: 166), но нужно опасаться того, что лишь кажется символом. Чтобы быть символом, нужно выполнять некоторые формальные условия - в частности, не нарушать грамматических правил и иметь свой объект. Примером нарушения первого условия является выражение «я были» $\left(\mathrm{I}_{\text {is }}^{6}\right)$. Примером нарушения второго служит парадокс лжеца.

5 На русском разбор семантики Пирса можно найти в: Кирющенко, 2008, более подробно см.: Short, 2007.

${ }^{6}$ Учитывая «кантианство» раннего Пирса, уместно сравнить это место с: $\mathrm{KrV}$, AA о3: В 422; а также: ibid.: В 627 . 
Какова роль обсуждения лжеца в третьей лекции? Эта лекция заявляется как посвященная теории вероятности, но почти на две трети состоит из обучения слушателей нотации булевой алгебры с использованием прообраза современных таблиц истинности. Легко представить, насколько необычен и сложен для восприятия слушателей того времени был излагаемый Пирсом материал, так что лектор решил завершить свою сухую техническую лекцию обсуждением популярных софизмов: он опровергает софизм Мелисса о безначалии мира7, софизм о молчуне, для которого невозможно заговорить, ведь невозможно для молчащего говорить, а также парадокс Зенона о стреле, софизм «Рогатый» и - под самый конец - парадокс лжеца. Пирс отмечает, что это «куда более сложный случай» $\left(\mathrm{W}_{1}: 202\right)$ и завершает свое рассмотрение на высокой ноте: он заявляет, что не знает вопроса, от которого бы в большей степени зависело человеческое счастье, - от правильного решения здесь зависит открытие тайн свободы воли, божественности и бессмертия (ibid.: 204).

Так какое же решение предлагает Пирс? В 1865 г. он сосредоточен на первых двух характеристиках: осмысленности и истинности. Подход Пирса таков. Условием осмысленности суждения является наличие у него своего объекта (т. е. референта). Пирс понимает «наличие объекта» как «наличие отношения к чему-то внешнему». Пирс упрекает «лжеца» в том, что он говорит лишь о самом себе. Он буквально зациклен на себе и не может прорваться к чему-то вне себя. Пытаясь понять смысл суждения «это суждение ложно», мы могли бы спросить: о чем оно? Разумный ответ будет: оно о себе. Спросим вновь: а о чем это, о себе? Ответ будет такой же: о себе о себе. Ясно, что тут мы попадаем в дурную бесконечность. Рассматриваемое суждение буквально говорит нам, что у него нет собственного объекта. Поэтому парадокс лжеца не имеет смысла.

Что можно сказать о его истинности? «Факт в том, что в этом суждении истина и неистина, утвердительное и отрицательное, это и иное совпадают. Оно стоит на границе Истины и Ложного-и поэтому принадлежит обоим» (ibid.: 203). Ясно, что нам нужно выбрать из двух вариантов: «лжец» либо не истинен и не ложен, либо и истинен, и ложен. Чтобы разобраться с этим, Пирс приводит пример с листком бумагичастично красным, частично голубым. Верно, что каждая точка на

${ }^{7}$ Аристотель излагает этот аргумент и критикует его в Soph. El. 5, 167b, 15-20 (Аристотель, Иткин, 1978: 543). Пирс тут следует за Стагиритом. 
листе либо красная, либо голубая. А что насчет разделительной линии? Составляющие ее точки либо красные и голубые, либо ни красные, ни голубые. Кажется, что второй вариант более привлекателен, ведь цвет есть атрибут протяженности, а точки таковой не обладают. Но это, считает Пирс, ложный путь, поскольку, хотя цвету действительно нужна протяженность, из этого не следует, что точки линии не обладают цветом, ведь движение, например, есть отношение между двумя точками, а тем не менее оно существует в каждой точке (W1: 204). Таким образом, для прояснения парадокса лжеца он привлекает свое же решение парадокса Зенона. Второй довод против того, что линия ни красная, ни голубая, таков: если разделительная линия ни красная, ни голубая, то ничто на листе ни красное, ни голубое, потому что мы не можем передвинуть линию в любую точку листа без того, чтобы изменить ее цвет.

Иными словами, в гарвардских лекциях 1865 г. Пирс утверждает:

(1) суждение «это суждение ложно» бессмысленно;

(2) суждение «это суждение ложно» и истинно, и ложно.

Этот подход легко поставить под сомнение. Первое, что бросается в глаза исследователям, - это то, что «и истинно, и ложно» так же противоречиво, как и «не истинно и не ложно», которое Пирс отвергает, по их мнению, как самопротиворечивое (Michael, 1975: 371; Atkins, 2011: 442). Это верно, но не отменяет того факта, что Пирс принимает свое решение на основе несколько иного аргумента.

Есть и другие способы критиковать решение 1865 г. Что насчет суждения «это суждение истинно»? Как быть с такими случаями как «в этом суждении шесть слов» или «в этом суждении не упомянуты мамы»? Эти суждения так же говорят лишь о себе, а между тем у нас нет проблем с определением их значения: первое суждение истинно, второе и третьеложны. Можно попытаться парировать это тем, что второе и третье включают в себя представления о, соответственно, словах и мамах, но если это является основанием для осмысленности, то почему таковым не является представление о суждениях и истинностной оценке? В любом случае, первое суждение не упоминает ни о чем, о чем бы ни говорилось в парадоксе лжеца. Что касается суждения «это суждение истинно», то в рукописи «Непсихологический взгляд на логику, к которому прилагаются некоторые приложения теории к психологии и другим предметам» 
(MS: $\left.726^{8}\right)$, датируемой Robin index примерно 1865 г., мы встречаем такое рассуждение: «Снова рассмотрим это суждение „это суждение истинно"9. Почему оно так абсурдно? Потому что оно не имеет референиии к обгекту, опосредованной или непосредственной ${ }^{10} \gg$. Таким образом, Пирс последователен в своей позиции.

Условие наличия объекта также не кажется чем-то необходимым для того, чтобы получить пропуск в зону ответственности принципа исключенного третьего. Ведь суждение «Глокая куздра штеко будланула бокра» грамматически корректно, как и «это суждение ложно». Суждение, отвечающее условию отсутствия объекта и потому могущее быть названным бессмысленным, может также рассматриваться с точки зрения указанного логического принципа: известная куздра либо штеко будланула бокра, либо нет, что бы это ни значило.

Словом, это решение никак не может быть рассмотрено как удачное, и Пирс довольно быстро изменил свою точку зрения.

\section{РЕШЕНИЕ 1869 ГОДА}

Второе решение Пирса предложено им в работе «Основания силы законов логики: дальнейшие следствия четырех неспособностей». Неспособности, о которых идет речь в названии статьи, - неспособность к интуиции, интроспекции, познанию без знаков и мышлению понятия «абсолютное непознаваемое». Они были проанализированы в предшествующей работе, которая называлась «Некоторые следствия четырех неспособностей», а предпосылки были заложены в статье «Вопросы, касающиеся некоторых способностей, приписываемых человеку». Эти три статьи образуют т. н. «серию о познании» (cognition series) и содержат, вероятно, самые известные идеи Пирса о реальности и познании. В отношении известности с ними могут конкурировать только «Как сделать наши идеи ясными» и «Закрепление убеждений». Статьи были опубликованы в «Журнале спекулятивной философии» ${ }^{11}$, издаваемом лидером сент-луисовских гегельянцев Уильямом Харрисом (Peirce,

8 Здесь и далее манускрипты и письма Пирса, в соответствии с общепринятой практикой, цитируются по номеру согласно Robin index (Robin, 1967).

9 Изначально в рукописи написано «false», но рукой Пирса зачеркнуто и сверху написано «true».

${ }^{10}$ Курсивом передано подчеркивание Пирса.

${ }^{11}$ Данное издание иногда называют первым философским журналом Америки (W2: XXV). Это не совсем точно: как заметил Д. В. Ермоленко, с 1769 г. в США издавался журнал «Transactions of the American Philosophical Society» (Ермоленко, 1965: 4). Впрочем, статьи, публикуемые в этом издании, не принадлежат к профессиональной философии, 
1868a,b; 1869) ${ }^{12}$. В молодом тогда журнале публиковались, как правило, переводы немецких идеалистов. Вся деятельность Пирса в рамках этого журнала (она также включала заметки «Nominalism versus Realism» и «What Is Meant by 'Determined'») была ответом на эпистолярно брошенный Пирсу вызов гегельянца Харриса объяснить силу законов логики, исходя из своих, тогда номиналистических, позиций (W2: 243). И именно в третьей статье цикла Пирс выстраивает свой антифундаменталисткий ответ. Статья Пирса-открывающая статья единственного выпуска 1869 г., в котором также было напечатано продолжение перевода «Феноменологии духа», сделанного Генри Брокмейром (Brockmeyer) и Харрисом, и статьи, посвященные актуальной немецкой философии, а также перевод «Санкхья-карики».

Первые две статьи серии о познании представляли собой атаку на картезианскую эпистемологию; третья также открывается этой темой. Пирс пытается дедуцировать логические законы в смысле оправдания справедливости их притязаний ${ }^{13}$. Он показывает, что вся логика зависит от принципа, согласно которому если некий знак означает то же, что и второй знак, а второй знак значит то же, что и третий знак, первый знак означает то же, что и третий знак. Если это верно, то формальная логика работает. Нужно лишь защитить ее от нападок скептиков, говорящих, что все упирается в некие первые постулаты, что большая посылка уже содержит заключение, что исчисление есть лишь механический процесс, а потому не может идеально отражать живое мышление. Стоит также отвести гегелевские придирки в односторонности, субъективности и в том, что из истинных посылок по правилам силлогистики можно прийти к ложным выводам ${ }^{14}$. Проделав все это, Пирс берется за вторую угрозу, а именно софизмы, которые некоторые полагают неразрешимыми с позиций формальной логики:

и хотя авторы $J_{o S P}$ тоже были любителями, все же они любили именно профессиональную философию.

${ }^{12}$ Позднее работы были опубликованы во второй книге пятого тома Collected Papers ( $\left.\mathrm{CP}_{5}: 213-357\right)$, получив специфическую разбивку и подзаголовки, которые используются и авторами русских переводов (Пирс, Голубович и др., 200оа; Пирс, Голубович и др., 200оb; Пирс, Кирющенко и Колопотин, 200ос; Пирс, Кирющенко и Колопотин, 200оd). Я ориентируюсь на издание «Writings of Charles S. Peirce» (W2: 193-272).

${ }^{13} \mathrm{Cp} .: \mathrm{KrV}, \mathrm{AA}$ 03: B 117 .

${ }^{14}$ Пирс остроумно показывает, что все дело в том, что Гегель на самом деле берет для своих примеров ложные посылки и строит формально неправильные силлогизмы. Все рассмотрение заканчивается тонкой философской шуткой, сравнимой с шуткой Рассела про парик (Гегель, Столпнер, 1972: 113-114; Рассел, Суровцев, 2007: 24). 
парадокс Зенона, парадокс «настоящий Горгий» (который напоминает т. н. «взрывоопасность логического следования») и парадокс лжеца.

Теперь Пирс принимает, что аттестация суждения как одновременно истинного и ложного ведет к противоречию так же, как ведет к нему аттестация его как ни истинного, ни ложного (W2: 261). Пирс согласился с тем, что объектом суждения может быть суждение, а значит, суждение может быть объектом самого себя, и это никак не мешает его осмысленности. Во всяком случае, философ утверждает, что у суждения «это суждение ложно» есть смысл (meaning). Более того, он даже не считает, что самопротиворечивые суждения бессмысленны, просто они значат слишком многое, а именно - две взаимоисключающие вещи. Таким образом, решение 1869 г. сосредоточено на второй характеристике: на истинности.

Это новое решение исходит из представления, заимствованного у Павла Венецианского: согласно ему, любое суждение скрыто имплицирует собственную истинность. Сегодня мы могли бы выразить это так: «p»ト «,p истинно“». «Москва - столица России» и «я принимаю, что Москва - столица России» - это одно и то же с точки зрения истинности. В таком случае источником парадокса является простое противоречие между скрытым и явным утверждениями, которые делает лжец. «Обсуждаемое суждение, следовательно, истинно во всех других аспектах, кроме его импликации своей собственной истинности» (ibid.: 263). Иными словами, Пирс утверждает, что

(1) суждение «Это суждение ложно» самопротиворечиво;

(2) суждение «Это суждение ложно» ложно.

Это решение не выглядит безупречным. Особую трудность представляет принцип, согласно которому суждения утверждают собственную истинность. Но Пирс придерживается его вплоть до начала ХХ в., когда он отказывается от своего второго пути решения парадокса лжеца. В прочитанных в 1903 г. гарвардских лекциях о прагматизме он отрицает, что решение 1869 г. имеет силу, и называет его petitio principii, обращая внимание на то, что суждения «идет дождь» и «я считаю истинным (assert), что идет дождь» не являются эквивалентными, что предсказывается теорией 1869 г. Теперь он не согласен с тем, что суждение само в себе содержит утверждение о своей истинности: такое представление было бы тем же самым, что и утверждение, будто желание содержит в себе свое собственное удовлетворение (ЕР2: 169; Atkins, 2011: 424-428). Лишь рациональные деятели (а не сами суждения) способны утверждать истинность или ложность суждений, а для этого они 
должны принимать или не принимать их. Таким образом разрушается основание для решения 1869 г.

«ПОЗДНИЙ» ПИРС: ИССЛЕДОВАНИЯ НАЧАЛА ХХ В.

Прежде чем отказаться в 1903 г. от решения 1869 г., в 1901 г. Пирс написал для словаря по философии и психологии, который выходил под редакцией Дж. Болдуина, статью «Insolubilia», в которой описал парадокс лжеца и два возможных метода его решения: решение Оккама, согласно которому не может быть такого суждения, как суждение лжеца, ведь ни одно суждение не может утверждать ничего о самом себе, и решение Павла Венецианского, согласно которому каждое суждение утверждает свою истину, что означает самопротиворечивость и ложность суждения лжеца. Пирс также ссылается на Якоба Фридриха Фриза, который утверждал, что так как каждое суждение утверждает свою истинность, то ни одно суждение не может утверждать свою ложность. Сам Пирс в данной статье ни к какому решению не присоединяется (Peirce, 1901: 554). Рэндалл Диперт считает, что именно эта статья возродила интерес философской общественности к парадоксу лжеца (Dipert, 2004: 291). Почему? Диперт утверждает, что эта статья привлекла внимание молодого Бертрана Рассела (ibid.: 320). Исследователь, однако, не дает никаких оснований согласиться с ним в этом вопросе. Между тем, если то, что он заявляет, соответствует действительности, то мы можем говорить о прямом влиянии Пирса на одного из основателей аналитической философии в критический момент его философской карьеры; о том, что не только парадокс Кантора, как об этом пишет сам Рассел (Russell, 1903: 101), послужил источником вдохновения для открытия парадокса нормального множества, но и пирсовское видение парадокса лжеца.

Некоторые основания в пользу мнения Диперта можно найти: Рассел ссылается на Пирса в своей статье «О „Insolubilia“ и их решении символической логикой» ${ }^{15}$. Этот факт, правда, обосновывает лишь второе заявление Диперта, но не первое: Рассел цитирует статью из словаря, а значит, та действительно привлекла его внимание. Но Рассел вполне

${ }_{15}$ Так звучит оригинальное название, данное статье Расселом. Однако в печать текст вышел во французском переводе Луи Кутюра (Russell, 19o6: 632), который убедил своего британского коллегу изменить название на «Парадоксы логики», так как слово «Insolubilia» было не очень хорошо известно во Франции; впрочем, оно действительно плохо представляет расселовские рассуждения. Оригинальный английский текст опубликован в Russell, 2014 . 
мог не понять, кто является автором статьи, ведь та была подписана как «C.S.P.». У Рассела, впрочем, была возможность установить, чьи это инициалы, ведь он был знаком с некоторыми логическими работами Пирса; кроме того, расшифровку инициалов можно было найти в начале словаря. Это, однако, не так важно, поскольку статья была написана в 1906 г., то есть через четыре года после того, как было отправлено знаменитое письмо к Фреге. Впрочем, Рассел мог бы прочесть статью Пирса между 1901 и 1902 гг., а сослаться на нее только в 1906. Но содержательно ссылка на статью Пирса не является необходимой для аргументации Рассела и выполняет лишь барочную функциюпозволяет Расселу «щегольнуть» историко-философскими знаниями, «прислониться» к авторитету Оккама и сказать, что выбраться из бесконечного регресса, к которому нас приводят суждения, говорящие о самих себе, нам поможет лишь переустройство логических принципов, более или менее напоминающее то, что совершил Рассел в своей логической теории. Последнее замечание позволяет Расселу посетовать, что Анри Пуанкаре, идеи которого в данной статье являются объектом критики, не понимает, в отличие от Оккама, необходимости такого переустройства. Таким образом, подтвердить первое заявление Диперта не представляется возможным, - во всяком случае, мне неизвестны удачные попытки это сделать,- что, однако, не отменяет возможности концептуального сравнения пирсовских решений парадокса лжеца и расселовской теории типов ${ }^{16}$.

На этом тему связи Пирса и Рассела можно было бы оставить, если бы в архиве Пирса не хранился небольшой документ, редко привлекавший внимание исследователей,- MS: 818. На неполных пяти страницах Пирс излагает свои соображения относительно парадокса, о котором он прочел у Рассела. Ниже привожу свой перевод своей же расшифровки части текста этой рукописи:

В двух недавних заметках последнего тома Рассела и Уайтхеда я видел следующее самопротиворечивое ${ }^{17}$ изложение - я изменил лишь формулировки.

Если некое $X^{18}$ не включает само себя, оно включает $W^{19}$.

${ }^{16}$ См. например: Thompson, 1949: $5^{21-} 5^{22}$.

${ }_{17}^{17}$ Пирс пишет просто «Self-», вероятно, сокращая.

${ }^{18} Я$ пишу переменные с прописной буквы, Пирс подчеркивает их и пишет со строчной. В этом и других случаях подчеркивания передаются курсивом. Вставки оригинальных слов приводятся в круглых скобках.

19 [it does] - очевидно, предложение оборвано. 
Если некий $X$ включает $W$, то он не включает самого себя.

Но предположим, что вместо логического отношения включения мы подставим обычное отношение между индивидами. Мы получим такую пару предложений, как показано ниже:

Тот, кто не любит самого себя, является любящим $W$. Если что-то является любящим $W$, оно не является любящим самого себя.

Эти два суждения просто подразумевают (imply), что ничто из природы $W$ не является самотождественным (self-identical). Это, вероятно, свойственно такой общей природе, как абстракция. Есть много вещей, о которых нужно рассуждать, которые не совсем существуют ${ }^{20}$.

В математике часто возникают такие явно противоречивые утверждения, но их легко толковать так, чтобы лишить их убедительности (MS: 818).

Отметим, что Пирс воспроизводит не сам парадокс Рассела, который возникает по поводу классов, а его применение к отношениям, которое, по Расселу (Russell, 1903: 102-103), к противоречию не ведет. Это не единственное размышление Пирса по поводу работы «Принципы математики» (1903), но, пожалуй, самое развернутое: остальные мы встречаем в очень скромной по объему рецензии, а также в письмах и в маргиналиях на полях его личного экземпляра (CP8: 171; MS: 12; ibid.: 459; ibid.: 499; L: 463; Anellis, 1995). Любопытно, что именно изложение парадокса Рассела - самая, вероятно, значимая часть этой книги, - привлекло внимание Пирса. Это, кстати, означает, что было бы весьма странно, если бы Пирс не знал при этом хотя бы некоторых идей Фреге ${ }^{21}$. Однако делать вывод об особой философской прозорливости Пирса или чувствительности по отношению к актуальным философским темам было бы неосторожно: возможно, то, что мы могли бы истолковать как особое внимание Пирса именно к парадоксу Рассела, представляет собой не более чем результат недостаточности источников наших знаний о занятиях Пирса «Принципами математики»в период после 1912 г.

${ }^{20}$ Предложение оборвано.

${ }^{21}$ Не говоря о том, что экземпляр «Begriffsschrift» хранился в библиотеке университета Джона Хопкинса в то время, когда там работал книголюб и эрудит Пирс. Кроме того, его ближайшие ученики точно были знакомы с содержанием книги немецкого логика. 
В завершении статьи я коснусь еще двух сюжетов: реконструкции третьего и невысказанного решения Пирса и связи «лжеца» с проблемой континуума и трехзначной логикой.

\section{ПОНИМАТЬ, НЕ ПРИНИМАТЬ}

Легко заметить, что в решениях 1865 и 1869 гг. нет ничего специфически прагматического (Thompson, 1949: 514). Это и понятно: «прагматизм» появляется на заседаниях Метафизического клуба, а значит, специфически прагматические мотивы вряд ли могли появиться до 1872 г. Впрочем, как мы уже видели, и в работах 1900-х гг. не наблюдается какого-то особо прагматического подхода к проблеме. Поэтому возникает вопрос: а что мог бы сказать Пирс-прагматист о «лжеце»? В конце концов, сформулировал же он свою теорию истины; что будет, если применить ее к нашему случаю, ведь именно истина тут и является источником проблем? Насколько мне известно, Пирс сам никогда такую работу не производил. За него ее сделал Ричард Эткинс (Atkins, 2011).

В то время как решение 1865 г. исследовало вопросы осмысленности и истинности, а подход 1869 г. был полностью сконцентрирован на истинности, то, что Эткинс реконструирует в качестве философского подхода позднего Пирса, концентрируется на значимости (сам он, впрочем, такой терминологии, как и Пирс, не использует). Делает он это, опираясь на прагматическую теорию истины и на различие «принятия» (assertion) и «понимания» (assent). «Принимать что-то» означает «быть готовым взять на себя ответственность за последствия». Несмотря на то, что мы понимаем суждение «это суждение ложно», мы не обязаны принимать его. А если мы не принимаем его, то от «это суждение ложно» не получится перейти ни к «,это суждение ложно“ ложно», ни к «,это суждение ложно“ истинно», что необходимо для того, чтобы прийти к парадоксу. При этом из рассуждения Пирса-Эткинса становится ясно, что дело вовсе не в субъективном, личном отношении некоего деятеля к парадоксу лжеца - иначе все бы зависело от произвола этого деятеля, и кто-то бы мог утверждать, что он-то принимает суждение «это суждение ложно». Нет, дело обстоит таким образом, что рациональный деятель не может принять парадокс лжеца так же, как он не может самостоятельно летать. Попытка принятия суждения «это суждение ложно» аналогична попытке полета, которая заканчивается падением. Таким образом, психологическая трактовка теории принятия не работает.

Антипсихологическая теория принятия следует из пирсовского понимания истины. В данной статье у меня нет возможности осветить 
все детали этого вопроса, но для наших целей достаточно сказать, что истинное суждение, по Пирсу, - это такое суждение, которое никогда вас не разочарует (Misak, 2016). Некоторое суждение может признаваться истинным, если достаточно долгое исследование не показало, что оно ложно. Следовательно, принимая что-то как истинное, вы также соглашаетесь нести ответственность за то, что оно истинное, и за все, что из этого следует. Никто, считает Пирс в реконструкции Эткинса, не может согласиться принять ответственность за суждение «это суждение ложно», так как простое рассуждение показывает, что это суждение не истинно. Другой важный аспект теории истины Пирса состоит в отрицании того, что истина является дуальным отношением, связывающим суждение и реальность. Вместо этого Пирс предлагает считать, что истина является троичным отношением, которое связывает суждение, реальность и рациональных агентов. Поэтому акт принятия получает социальное измерение.

Нет ли тут, правда, проблемы в том, что мы не принимаем суждение «это суждение ложно» и не считаемся с его следствиями, но откуда-то знаем, что это за следствия, поскольку именно это знание и является основанием для нашего отказа принять суждение «это суждение ложно»? В ответ на это Пирс Эткинса и прибегает к различию «принимать» и «понимать». Из того, что я понимаю следствия, которые можно вывести из суждения «это суждение ложно», не следует, что я принимаю их, ведь приятие - это не столько логический, сколько социальный акт, так как оно связано с ответственностью.

Правда, и этого Эткинс не учитывает, тогда парадокс возникает внутри нашего понимания (assent). Мы понимаем парадоксальность исследуемого суждения и потому отказываемся иметь с ним дело. Возможно, это лучшее, что можно тут сделать. Парадокс, однако, никуда не уходит.

\section{ТРЕХЗНАЧНАЯ ЛОГИКА И КОНТИНУУМ}

Исследуя истинность суждения «лжеца», мы упоминали вариант «ни истина, ни ложь». В 1865 г. Пирс отбрасывает его, а в 1869 г. просто не рассматривает. А между тем он кажется вполне привлекательным. Если «лжец» говорит ни истину, ни ложь, то как оценить то, что он говорит? Нужно какое-то новое, третье истинностное значение, то есть нужно создать трехзначную логику. И как раз Пирсу принадлежит пальма первенства в этой области. Впервые об открытии Пирса миру поведали Макс Фиш и Атвел Таркет (Fisch \& Turquette, 1966). Именно 
Фиш и Таркет обратили внимание на MS: 339, датируемый 23 февраля 1909 г., где Пирс излагает свои эксперименты, связанные с трехзначной логикой, и показали, что Пирс предвосхитил исследования Я. Лукасевича и Э. Поста по меньшей мере на десять лет. Правда, работа Пирса была этим ученым неизвестна.

Пирс считает двузначную логику ограниченной, хотя и не абсолютно ложной. Он пишет:

...каждое суждение, имеющее форму «S есть $P »$, либо истинно, либо ложно, и еще либо способ бытия $S$ ниже, чем такой, какой требуется для того, чтобы быть или определенно $P$, или определенно не- $P$, но находится на границе между $P$ и не- $P^{22}$ (ibid.).

Фиш и Таркет считали, что Пирс создал трехзначную логику в попытках решить проблемы истинностной оценки модальности, общих и т. н. «неясных» суждений. Так, Пирс пишет, что утверждение о возможности свободно от принципа непротиворечия ${ }^{23}$, но зависит от принципа исключенного третьего, а суждения о необходимости зависят от принципа непротиворечия, но свободны от принципа исключенного третьего (ibid.: 642; ibid.: 678), так как неверно было бы сказать, что необходимое суждение истинно или неистинно. Если трехзначной логике отходят возможность и необходимость, то двузначной остается царство актуального. Главным мотивом появления трехзначной логики тогда оказывается тихизм - учение Пирса о важности случайности. Доставляют трудности и общие, а также т. н. «неопределенные» суждения. Кроме того, в 1905 г. Пирс пишет, что все общее (general) свободно от принципа исключенного третьего, а все «неясное» (vague) свободно от принципа непротиворечия ( $\left.\mathrm{CP}_{5}: 448\right)$.

Слабостью своего похода Фиш и Таркет считали его неспособность объяснить время появления пирсовых исследований по трехзначной логике. Пирс разработал учение о модальности еще в юности-так почему только под конец жизни он решился его формализовать? Они также высказывают интересное, но малообоснованное предположение, что идеи Пирса могли быть стимулированы дискуссией между Хью МакКоллом и Бертраном Расселом о статусе переменных: МакКолл

${ }^{22} S$ has a lower mode of being such that it can neither be determinately $P$, nor determinately not- $P$, but is at the limit between $P$ and not $P$.

${ }^{23}$ Так как «возможность» означает позитивную способность «быть Да и быть $H е т »$ (MS: 277). 
защищал взгляды, во многом похожие на идеи Пирса. Сегодня широко признано, что именно Пирс и МакКолл являются создателями многозначной логики (Карпенко, 2016: 39)

Поход Фиша и Таркета был подвергнут серьезной критике со стороны Роберта Лейна, который показал, что идеи трехзначной логики не связаны у Пирса ни с учением об общем и неопределенном, ни с теорией модальностей (Lane, 1997; 1999). Лейн показывает, Пирс делит все суждения на determinate, определенные (те, чей субъект отсылает к кому-то объекту), и indeterminate, неопределенные (те, чей субъект не обладает таким свойством). Неопределенные суждения он делит на неясные, vague (или indefinite), и общие, general. Первые называются неясными из-за характера местоимений, с помощью которых они чаще всего образуются: «некоторые», «какие-то», «несколько» и т. п. Примером общего суждения является «человек смертен». Примером неопределенного суждения - «человек, которого я могу упомянуть, кажется немного тщеславным» (CP $5: 447-448)$.

Второе уточнение, которое делает Лейн: в ibid.: 448 и схожих местах Пирс, говоря о законах логики, имеет в виду их формулировки с номинальным, а не вербальным,- внутренним, а не внешним отрицанием. Для определенных суждений внутреннее и внешнее отрицание образуют противоречия: «этот помидор красный» переходит в «этот помидор не красный» и «неверно, что это помидор красный». Но для неопределенных суждений не все так просто: внутреннее отрицание для общих суждений образует не контрадикторное суждение, а контрарное: «все люди смертны» переходит в «все люди не смертны». Эти суждения могут быть одновременно ложны. Внутреннее отрицание для частных суждений образует субконтрарные суждения: «некоторые люди тщеславны» и «некоторые люди не тщеславны» могут быть одновременно истинны, но не могут быть одновременно ложны, если существует по крайней мере один человек. Таким образом, тот факт, что общие суждения в этом смысле свободны от принципа исключенного третьего, а частные суждения - от принципа непротиворечия, никак не затрагивает принципа бивалентности, потому что принцип исключенного третьего и принцип непротиворечия в данном случае не ложны, а неприменимы. Не угрожают ему и свойства модальных суждений: тут Лейн различает «быть неприменимым» и «быть ложным в отношении чего-то». Принцип непротиворечия просто ничего не говорит о возможностях, а принцип исключенного третьего-о необходимости. Условиями применимости закона исключенного третьего Пирс считает то, что суждение должно 
быть не общим и суждение должно не быть суждением о необходимости. Условия применимости закона непротиворечия: суждение должно быть не частным и суждение должно не выражать возможность.

Значение $L$ (limit) принимают суждения, к которым применим закон исключенного третьего, но он относительно них ложен; к ним также применим закон непротиворечия, и он истинен. Это значит, что их субъектом является индивид, и они не являются модальными. Тут Пирс обращается к кантовской ${ }^{24}$ схеме (MS: 515 ; KrV, AA о3: В 95-97) и приходит к выводу, что трехзначная логика применима к единичным суждениям. Примером таких единичных суждений служат суждения о границах. В том же MS: 339 Пирс приводит в пример черное пятно на бумаге и рассматривает статус точек, образующих разделительную линию между черным и нечерным. Суждение «,эта разделительная линия" черная» не является ни истинным, ни ложным, - оно является $L$ и лежит на границе (limit) между истиной и ложью так же, как сама линия разделяет черное и нечерное. То же можно сказать и о суждении «,эта разделительная линия" нечерная». Таким образом, трехзначная логика, по Лейну, есть инструмент работы с суждениями о нарушениях континуума. Иными словами, она нужна не для тихизма, а для синехизма.

Лейн считает, что такая реконструкция позволяет ему объяснить, почему трехзначная логика появляется именно в 1909 г., - потому что более ранние, кантовские (W2: 256; KrV, АA о3: В 211) взгляды Пирса на континуум определяли его позицию по вопросу суждениях о разрывах: они и $P$, и не- $P$. Лейн прослеживает эволюцию его взглядов в течение всей второй половины ХІХ в. и показывает, что лишь после 1898 г. Пирс начинает рассматривать континуум как собрание такого огромного множества точек, что во всей вселенной возможности нет места для того, чтобы они сохраняли отдельные идентичности, - поэтому они объединены друг с другом. Это ведет его к утверждению, что суждения о разрывах не истинны и не ложны, а находятся на пределе.

Несмотря на сделанные Лейном важные пояснения, его реконструкция неидеальна. Прежде всего, как замечает он сам (Lane, 1999: 297), не каждое изменение в концепции континуума напрямую вело к изменению понимания суждений о разрывах. Но действительно неудовлетворительной ситуация становится тогда, когда к обсуждению «связки»

24 Этого Лейн не говорит, но это вполне очевидно всякому, кто знаком с трансцендентальной аналитикой. 
континуума и трехзначной логики мы добавляем рассмотрение «лжеца», рассуждения о котором поясняются Пирсом как раз с помощью континуума, и потому парадокс лжеца может рассматриваться как пример суждения о разрыве. В рассмотренной статье 1869 г., где Пирс считает суждения о разрыве одновременно $P$ и не- $P$ (W2: 257), суждение «лжеца» он считает ложным, а вовсе не одновременно истинным и ложным! Можно предположить, что в 1865 г. «Лжец» связывался Пирсом с континуумом, а в 1869 г. эта связь исчезла. Тогда Лейну нужно объяснить, почему это произошло, поскольку никаких изменений в понимании континуума между 1865 и 1869 гг. он не фиксирует.

Таким образом, исследователям многозначности нужен какой-то новый подход к истории этой идеи.

\section{СОКРАЩЕНИЯ}

AA

$\mathrm{CP}_{5}$

CP8

$\mathrm{EP}_{2} \quad$ Peirce C.S. The Essential Peirce. In 2 vols. Vol. 2 / ed. by N. Houser,

Kant I. Gesammelte Schriften. - Berlin, 1900- .

Bd. 1-22 / hrsg. von der Preussischen Akademie der Wissenschaften.

Bd. 23 / hrsg. von der Deutschen Akademie der Wissenschaften zu Berlin.

Bd. 24 / hrsg. von der Akademie der Wissenschaften zu Göttingen. Peirce C. S. Collected Papers of Charles Sanders Peirce. In 8 vols. Vol. 5 / ed. by C. Harteshorne, P. Weiss. - Cambridge (Mass.) : Harvard University Press, 1934.

Peirce C.S. Collected Papers of Charles Sanders Peirce. In 8 vols. Vol. 8 / ed. by A. W. Burks. - Cambridge (Mass.) : Harvard University Press, 1958. C. Kloesel. - Bloomington (Indiana) : Indiana University Press, 1998.

$\mathrm{KrV}$, AA o3 Kant I. Kritik der reinen Vernunft // Gesammelte Schriften. Bd. 3. $\mathrm{L}$ Peirce C.S. [Letters]. - MS Am 1632, Houghton Library, Harvard Library, Harvard University.

MS

Peirce C.S. [Manuscripts]. - MS Am 1632, Houghton Library, Harvard Library, Harvard University.

Soph. El. Aristoteles. Sophistici Elenchi // Aristotelis Opera. Vol. I. Aristoteles Graece / Ed. I. Bekker. - Berlin, 1831. - P. 160-184.

$\mathrm{W}_{1}$

Peirce C.S. Writings of Charles S. Peirce: A Chronological Edition. In 8 vols. Vol. I. 1857-1866. - Bloomington (Indiana) : Indiana University Press, 1982. 
$\mathrm{W}_{2}$

$\mathrm{W}_{3}$

Peirce C.S. Writings of Charles S. Peirce: A Chronological Edition. In 8 vols. Vol. II. 1867-1871. - Bloomington (Indiana) : Indiana University Press, 1984 .

Peirce C.S. Writings of Charles S. Peirce: A Chronological Edition. In 8 vols. Vol. III. $187^{-18}-18$. - Bloomington (Indiana) : Indiana University Press, 1986.

\section{Источники}

Аристотель. О софистических опровержениях / пер. с древнегреч. М. И. Иткина // Сочинения. В 4 т. Т. 2 / под ред. З.Н. Микеладзе. - М. : Мысль, 1978. - C. $535^{-594}$.

Гегель Г. В.Ф. Наука логики. В 3 т. Т. 3 / под ред. А. П. Огурцова, М.И. Иткина ; пер. с нем. Б. Г. Столпнера. - М. : Мысль, 1972.

Диоген Лаэртский. О жизни, учениях и изречениях знаменитых философов / под ред. А. Ф. Лосева; пер. с древнегреч. М. Л. Гаспарова. - М. : Мысль, 1979.

Кант И. Пролегомены ко всякой будущей метафизике / пер. с нем. В. С. Соловьева // Собрание сочинений. В 8 т. Т. 4 / под ред. А.В. Гулыги. M. : Чopo, 1994. - C. $5^{-1} 5^{2}$.

Пирс Ч. С. Вопросы относительно некоторых способностей, приписываемых человеку // Избранные философские произведения / пер. с англ. К. О. Голубович, К. К. Чухрукидзе, Т. А. Дмитриева. - М. : Логос, 200оа. - С. 19-47.

Пирс Ч. С. Некоторые последствия четырех неспособностей // Избранные философские произведения / пер. с англ. К. О. Голубович, К. К. Чухрукидзе, Т. А. Дмитриева. - М. : Логос, 2000b. - С. 48-95.

Пирс Ч. С. Некоторые последствия четырех неспособностей // Начала прагматизма / пер. с англ. В. В. Кирющенко, М. В. Колопотина. - СПб. : Алетейя, 2000с. - С. $10^{-} 50$.

Пирс Ч. С. Основания силы законов логики: дальнейшие последствия четыре неспособностей // Начала прагматизма / пер. с англ. В.В.Кирющенко, М. В. Колопотина. - СПб. : Алетейя, 200od. - С. 51-91.

Pассел Б. Об обозначении / пер. с англ. В. А. Суровцева // Избранные труды. Новосибирск : Сиб. унив. изд-во, 2007. - С. 17-32.

Pассел Б. Существование бога / пер. с англ. А. А. Яковлева // Почему я не христианин. - М. : Опустошитель, 2016. - С. 254-281.

Тарский $A$. Семантическая концепция истины и основания семантики / пер. с англ. А. Л. Никифорова // Аналитическая философия: становления и развитие / под ред. А.Ф. Грязнова. - М. : Дом интеллектуальной книги, Прогресс-Традиция, 1998. - С. 90-129.

Фрагменты ранних греческих философов : от эпических теокосмогоний до возникновения атомистики. Т. I / пер. и сост. А. В. Лебедева. - М. : Наука, 1989. Фреге Г. Мысль: логическое исследование / пер. с нем. В. А. Суровцева // Логико-философские труды. - Новосибирск : Сиб. унив. изд-во, 2008. - С. 28-54. 
Юм Д. Трактат о человеческой природе. Книга 1. О познании / пер. с англ.

С. И. Церетели. - М. : Канон+, 2009.

Frege G. Frege on Russell's Paradox : Appendix to Vol. II / trans. from the German by P.T. Geach // Translations from the Philosophical Writings of Gottlob Frege / ed. by P. Geach, M. Black. - Oxford : Basil Blackwell, 1960. - P. 234-244.

Peirce C.S. Questions Concerning Certain Faculties Claimed for Man // Journal of Speculative Philosophy. - 1868a. - Vol. 2, no. 2. - P. 103-114.

Peirce C.S. Some Consequences of Four Incapacities // Journal of Speculative Philosophy. - 1868b. - Vol. 2, no. 2. - P. 140-157.

Peirce C.S. Grounds of Validity of the Laws of Logic// Journal of Speculative Philosophy. - 1869. - Vol. 2, no. 4. - P. 193-208.

Peirce C.S. Insolubilia // Dictionary of Philosophy and Psychology / ed. by J. M. Baldwin. - New York, London : The Macmillan co., 1901. - P. 554.

Russell B. The Principles of Mathematics. - Cambridge : at the University Press, 1903 .

Russell B. Les paradoxes de la logique // Revue de Métaphysique et de Morale. 1906. - T. $14, \mathrm{n}^{\circ}$ 5. - P. 627-650.

Russell B. The Collected Papers of Bertrand Russell. Vol. 5. Toward Principia Mathematica, 1905-08 / ed. by G. H. Moore. - London, New York : Routledge, 2014.

\section{ЛИтературА}

Брадвардин Т., Журавлева Е. В., Лисанюк Е. Н. Трактат о логических парадоксах // Историко-философский ежегодник 2013 / под ред. А. В. Черняева, Н. В. Мотрошиловой. - М. : Канон+, РООИ «Реабилитация», 2014. - С. 66-85.

Ермоленко Д. В. Современная буржуазная философия в США. - М. : Международные отношения, 1965 .

Карпенко А. С. Развитие многозначной логики. - М. : Из-во ЛКИ, 2016.

Кирющенко В. В. Язык и знак в прагматизме. - СПб. : Из-во ЕУ СПб, 2008. Логинов E. В. Прагматизм, истина и проблема значения // Эпистемология \& философия науки. - 2016. - Т. 50, № 4. - С. 151-167.

Мельвиль Ю. К. Чарльз Пирс и прагматизм. - М. : Изд-во МГУ, 1968.

Anellis I. H. Peirce Rustled, Russell Pierced // Modern Logic. - 1995. - Vol. 5, no. 3. - P. $270^{-} 328$.

Atkins R. K. This Proposition Is Not True: C. S. Peirce and the Liar Paradox // Transactions of the Charles S. Peirce Society. - 2011. - Vol. 47, no. 4. - P. 421-444. Ayer A. The Origins of Pragmatism. - San Francisco : Freeman, Cooper \& Company, 1968.

Brady G. From Peirce to Skolem. A Neglected Chapter in the History of Logic. Amsterdam : North Holland, 2000.

De Rijk L. M. Some Notes on the Mediaeval Tract De Insolubilibus, with the Edition of a Tract Dating from the End of the Twelfth Century // Vivarium. 1966. - No. 4. - P. $83^{-115}$. 
Dipert R. C. S. Peirce's Deductive Logic // The Cambridge Companion to Peirce / ed. by C. J. Misak. - Cambridge : Cambridge University Press, 2004. - P. 287-324. Fisch M., Turquette A. Peirce's Triadic Logic // Transactions of the Charles S. Peirce Society. - 1966. - Vol. 2, no. 2. - P. 71-85.

Fraassen B. van. Presupposition, Implication, and Self-Reference // Journal of Philosophy. - 1968. - Vol. 65, no. 5. - P. 136-152.

Geach P. T. On Insolubilia // Analysis. - 1954. - Vol. 15, no. 3. - P. 71-72.

Heijenoort J. van. From Frege to Gödel: A Source Book in Mathematical Logic, 1879-1931. - Cambridge (Mass.) : Harvard University Press, 1967.

Hookway C. Truth, Rationality, and Pragmatism: Themes from Peirce. - Oxford : Clarendon Press, 2000.

Kripke S. Outline of a Theory of Truth. Vol. 72. - 1975. - P. 690-716.

Lane R. Peirce's "Entanglement" with the Principles of Excluded Middle and Contradiction // Transactions of the Charles S. Peirce Society. - 1997. - Vol. 33, no. 3. - P. 680-703.

Lane R. Peirce's Triadic Logic Revisited // Transactions of the Charles S. Peirce Society. - 1999. - Vol. 35, no. 2. - P. 284-311.

Michael E. Peirce's Paradoxical Solution to the Liar's Paradox // Notre Dame Journal of Formal Logic. - 1975. - Vol. 16, no. 3. - P. 369-374.

Misak C. Cambridge Pragmatism: From Peirce and James to Ramsey and Wittgenstein. - Oxford : Oxford University Press, 2016.

Myrvold W. C. Peirce on Cantor's Paradox and the Continuum // Transactions of the Charles S. Peirce Society. - 1995. - Vol. 31, no. 3. - P. 508-541.

Parsons T. Assertion, Denial, and the Liar Paradox // Journal of Philosophical Logic. - 1984. - Vol. 13, no. 2. - P. 137-152.

Priest G. Logic of Paradox Revisited // Journal of Philosophical Logic. - 1984. Vol. 13, no. 2. - P. $153^{-179}$.

Robin R. Annotated Catalogue of the Papers of Charles S. Peirce. - Amherst : University of Massachusetts Press, 1967.

Short T. L. Peirce's Theory of Signs. - Cambridge : Cambridge University Press, 2007 .

Soames S. Philosophical Analysis in the Twentieth Century. Vol. 1. The Dawn of Analysis. - Princeton : Princeton University Press, 2003.

Soames S. The Analytic Tradition in Philosophy. Vol. 1. The Founding Giants. Princeton : Princeton University Press, 2014.

Thompson M. H. The Logical Paradoxes and Peirce's Semiotic // The Journal of Philosophy. - 1949. - Vol. 46, no. 17. - P. 513-536.

Yablo S. Paradox without Self-Reference // Analysis. - 1993. - Vol. 53, no. 4. P. $251-25^{2}$. 
Loginov, Ye. V. 2017. "Pirs i paradoks lzhetsa [Pierce and the Liar's Paradox]" [in Russian]. Filosofiya. Zhurnal Vysshey shkoly ekonomiki [Philosophy. Journal of the Higher School of Economics] I (4), 59-83.

\section{YEVGENIY LOGINOV}

PhD in Philosophy, Junior Researcher at the Analytical Service, Lomonosov Moscow State UNIVERSITY

\section{Pierce AND THE LiaR's PARADOX}

Abstract: The liar paradox is a well-known logical and philosophical paradox, yet it has always been a tough call for professional philosophers, and it played a critical role in the history of philosophy, logic, and even mathematics. I examine the works of the founder of pragmatism Charles Sanders Peirce and his approaches to this problem, and try to reconstruct the evolution of his views on this issue. We may approach the proposition "This proposition is not true" from three points of view: its meaning, its truth value and its significance. The earliest Peirce's approach focuses on the meaning and truth value. He argues that the proposition "This proposition is not true" is meaningless and at the same time both true and not true. He introduces this way of reasoning in the 1865 in his Harvard lectures on the logic of science. His second approach was presented in the article "Grounds of Validity of the Laws of Logic: Further Consequences of Four Incapacities", published in 1869. He rejected his earlier account and based a novel solution in truth value on a Scholastic philosopher Paul of Venice's statement that every proposition asserts its own truth. Thus, the proposition "This proposition is not true" implies assertion of its own truth and at the same time says that it is not true; ergo it is false inasmuch it is self-contradictory. In 1903 Peirce rejected this approach because for any proposition it is true that it is not equivalent to proposition "I assert this proposition". Peirce has never presented a third solution of the liar paradox, but there are three issues closely connected with the topic: Russell-Peirce connection, Peirce mature theory of truth, which may propose a way to solve the liar paradox focusing on its significance, and Peirce's development of triadic logic. I discuss them in the second part of the article.

Keywords: Pierce, Russell, Liar Paradox, Continuum, Three-Valued Logic, Truth.

\section{REFERENCES}

Anellis, I. H. 1995. "Peirce Rustled, Russell Pierced." Modern Logic 5 (3): 270-328.

Aristotel' [Aristotle]. 1978. "O sofisticheskikh oproverzheniyakh [On Sophistical Refutations]" [in Russian]. In vol. 2 of Sochineniya [Collected Works], ed. by Z. N. Mikeladze, trans. from the Ancient Greek by M. I. Itkin, 535-594. 4 vols. Moskva [Moscow]: Mysl'.

Aristoteles. 1831. "Sophistici Elenchi" [in Ancient Greek]. In Aristoteles Graece, vol. I of Aristotelis Opera, ed. by I. Bekker, 160-184. Berlin.

Atkins, R. K. 2011. "This Proposition Is Not True: C. S. Peirce and the Liar Paradox." Transactions of the Charles S. Peirce Society 47 (4): 421-444.

Ayer, A. 1968. The Origins of Pragmatism. San Francisco: Freeman, Cooper \& Company.

Bradvardin, T., Ye. V. Zhuravleva, and Ye. N. Lisanyuk. 2014. "Traktat o logicheskikh paradoksakh [Insolubilia]" [in Russian]. In Istoriko-filosofskiy yezhegodnik 2013 [History of Philosophy Yearbook, 2013], ed. by A. V. Chernyayev and N. V. Motroshilova, 66-85. Moskva [Moscow]: Kanon+ / ROOI "Reabilitatsiya". 
Brady, G. 2000. From Peirce to Skolem. A Neglected Chapter in the History of Logic. Amsterdam: North Holland.

De Rijk, L. M. 1966. "Some Notes on the Mediaeval Tract De Insolubilibus, with the Edition of a Tract Dating from the End of the Twelfth Century." Vivarium, no. 4: 83-115.

Diogen Laert.skiy [Diogenes Laërtius]. 1979. O zhizni, ucheniyakh $i$ izrecheniyakh znamenitykh filosofov [Lives and Opinions of Eminent Philosophers] [in Russian]. Ed. by A.F. Losev. Trans. from the Ancient Greek by M. L. Gasparov. Moskva [Moscow]: Mysl'.

Dipert, R. 2004. "C. S. Peirce's Deductive Logic." In The Cambridge Companion to Peirce, ed. by C. J. Misak, 287-324. Cambridge: Cambridge University Press.

Fisch, M., and A. Turquette. 1966. "Peirce's Triadic Logic." Transactions of the Charles S. Peirce Society 2 (2): 71-85.

Fraassen, B. C. van. 1968. "Presupposition, Implication, and Self-Reference." Journal of Philosophy 65 (5): 136-152.

Frege, G. 1960. "Frege on Russell's Paradox: Appendix to Vol. II." In Translations from the Philosophical Writings of Gottlob Frege, ed. by P. Geach and M. Black, trans. from the German by P. T. Geach, 234-244. Oxford: Basil Blackwell.

Frege, G. 2008. "Mysl': logicheskoye issledovaniye [Der Gedanke. Eine logische Untersuchung]" [in Russian]. In Logiko-filosofskiye trudy [Collected Works], trans. from the German by V. A. Surovtsev, 28-54. Novosibirsk: Sib. univ. izd-vo.

Geach, P. T. 1954. "On Insolubilia." Analysis 15 (3): 71-72.

Gegel', G. V.F. [Hegel, G.W. F.] 1972. [in Russian]. Vol. 3 of Nauka logiki [Die Wissenschaft der Logik], ed. by A. P. Ogurtsov and M. I. Itkin, trans. from the German by B. G. Stolpner. 3 vols. Moskva [Moscow]: Mysl'.

Heijenoort, J. van. 1967. From Frege to Gödel: A Source Book in Mathematical Logic, 1879-1931. Cambridge (Mass.): Harvard University Press.

Hookway, C. 2000. Truth, Rationality, and Pragmatism: Themes from Peirce. Oxford: Clarendon Press.

Kant, I. 1900-. Gesammelte Schriften [in German]. Vol. 1-22: Ed. by Preussische Akademie der Wissenschaften. Vol. 23: Ed. by Deutsche Akademie der Wissenschaften zu Berlin. Vol. 24: Ed. by Akademie der Wissenschaften zu Göttingen. Berlin.

- 1994. Prolegomeny ko vsyakoy budushchey metafizike [Prolegomena zu einer jeden künftigen Metaphysik, die als Wissenschaft wird auftreten können] [in Russian]. In vol. 4 of Sobraniye sochineniy [Collected Works], by I. Kant, ed. by A. V. Gulyga, trans. from the German by V.S. Solov'yev, 5-152. 8 vols. Moskva [Moscow]: Choro.

Karpenko, A.S. 2016. Razvitiye mnogoznachnoy logiki [The Development of Many-Valued Logic] [in Russian]. Moskva [Moscow]: Iz-vo LKI.

Kiryushchenko, V. V. 2008. Yazyk $i$ znak $v$ pragmatizme [Language and Sign in Pragmatism] [in Russian]. Sankt-Peterburg [Saint Petersburg]: Iz-vo YeU SPb.

Kripke, S. 1975. Outline of a Theory of Truth. 72:69o-716. 19.

Lane, R. 1997. "Peirce's 'Entanglement' with the Principles of Excluded Middle and Contradiction." Transactions of the Charles S. Peirce Society 33 (3): 680-703.

- . 1999. "Peirce's Triadic Logic Revisited." Transactions of the Charles S. Peirce Society 35 (2): $284-311$.

Lebedev, A. V., comp. 1989. Fragmenty rannikh grecheskikh filosofov [The Fragments of the Early Greek Philosophers]: ot epicheskikh teokosmogoniy do vozniknoveniya atomistiki [From the Epic Theocosmogonies to the Birth of the Atomistics] [in Russian]. Trans. by A. V. Lebedev. Vol. I. Moskva [Moscow]: Nauka. 
Loginov, Ye. V. 2016. "Pragmatizm, istina i problema znacheniya [Pragmatism, Truth, and the Problem of Meaning]" [in Russian]. Epistemologiya \&6 filosofiya nauki [Epistemology E Philosophy of Science] 50 (4): 151-167.

Mel'vil', Yu. K. 1968. Charl'z Pirs i pragmatizm [Charles Peirce and Pragmatism] [in Russian]. Moskva [Moscow]: Izd-vo MGU.

Michael, E. 1975. "Peirce's Paradoxical Solution to the Liar's Paradox." Notre Dame Journal of Formal Logic 16 (3): 369-374.

Misak, C. 2016. Cambridge Pragmatism: From Peirce and James to Ramsey and Wittgenstein. Oxford: Oxford University Press.

Myrvold, W. C. 1995. "Peirce on Cantor's Paradox and the Continuum." Transactions of the Charles S. Peirce Society 31 (3): 508-541.

Parsons, T. 1984. "Assertion, Denial, and the Liar Paradox." Journal of Philosophical Logic 13 (2): $137-152$.

Peirce, C.S. 1868a. "Questions Concerning Certain Faculties Claimed for Man." Journal of Speculative Philosophy 2 (2): 103-114.

- . 1868b. "Some Consequences of Four Incapacities." Journal of Speculative Philosophy 2 (2): $140-157$.

- . 1869. "Grounds of Validity of the Laws of Logic." 2 (4): 193-208.

- . 1901. "Insolubilia." In Dictionary of Philosophy and Psychology, ed. by J. M. Baldwin, 554. New York and London: The Macmillan co.

- . 1934. . Vol. 5 of Collected Papers of Charles Sanders Peirce, ed. by C. Harteshorne and P. Weiss. 8 vols. Cambridge (Mass.): Harvard University Press.

- . 1958. . Vol. 8 of Collected Papers of Charles Sanders Peirce, ed. by A. W. Burks. 8 vols. Cambridge (Mass.): Harvard University Press.

- . 1982. 1857-1866. Vol. I of Writings of Charles S. Peirce: A Chronological Edition. 8 vols. Bloomington (Indiana): Indiana University Press.

- . 1984. 1867-1871. Vol. II of Writings of Charles S. Peirce: A Chronological Edition. 8 vols. Bloomington (Indiana): Indiana University Press.

- .1986. 1872-1878. Vol. III of Writings of Charles S. Peirce: A Chronological Edition. 8 vols. Bloomington (Indiana): Indiana University Press.

- . 1998. . Vol. 2 of The Essential Peirce, ed. by N. Houser and C. Kloesel. 2 vols. Bloomington (Indiana): Indiana University Press.

- . [Letters]. MS Am 1632, Houghton Library, Harvard Library, Harvard University.

- . [Manuscripts]. MS Am 1632, Houghton Library, Harvard Library, Harvard University.

Pirs, Ch. S. [Peirce, C. S.] 2000a. "Voprosy otnositel'no nekotorykh sposobnostey, pripisyvayemykh cheloveku [Questions Concerning Certain Faculties Claimed for Man]" [in Russian]. In Izbrannyye filosofskiye proizvedeniya [Selected Philosophical Works], trans. from the English by K. O. Golubovich, K. K. Chukhrukidze, and T. A. Dmitriyev, 19-47. Moskva [Moscow]: Logos.

- . 200ob. "Nekotoryye posledstviya chetyrekh nesposobnostey [Some Consequences of Four Incapacities]" [in Russian]. In Izbrannyye filosofskiye proizvedeniya [Selected Philosophical Works], trans. from the English by K. O. Golubovich, K. K. Chukhrukidze, and T. A. Dmitriyev, 48-95. Moskva [Moscow]: Logos.

- . 2000c. "Nekotoryye posledstviya chetyrekh nesposobnostey [Some Consequences of Four Incapacities]" [in Russian]. In Nachala pragmatizma [Elements of Pragmatism], trans. from the English by V. V. Kiryushchenko and M. V. Kolopotin, 10-50. Sankt-Peterburg [Saint Petersburg]: Aleteyya.

- . 200od. "Osnovaniya sily zakonov logiki: dal'neyshiye posledstviya chetyre nesposobnostey [Grounds of Validity of the Laws of Logic: Further Consequences of Four Incapacities]" [in 
Russian]. In Nachala pragmatizma [Elements of Pragmatism], trans. from the English by V. V. Kiryushchenko and M. V. Kolopotin, 51-91. Sankt-Peterburg [Saint Petersburg]: Aleteyya.

Priest, G. 1984. "Logic of Paradox Revisited." Journal of Philosophical Logic 13 (2): 153-179. Rassel, B. [Russell, B.] 2007. "Ob oboznachenii [On Denoting]" [in Russian]. In Izbrannyye trudy [Selected Works], trans. from the English by V. A. Surovtsev, 17-32. Novosibirsk: Sib. univ. izd-vo.

- . 2016. "Sushchestvovaniye boga [The Existence of God]" [in Russian]. In Pochemu ya ne khristianin [Why I'm Not a Christian], trans. from the English by A. A. Yakovlev, 254-281. Moskva [Moscow]: Opustoshitel'.

Robin, R. 1967. Annotated Catalogue of the Papers of Charles S. Peirce. Amherst: University of Massachusetts Press.

Russell, B. 1903. The Principles of Mathematics. Cambridge: at the University Press.

- . 1906. "Les paradoxes de la logique" [in French]. Revue de Métaphysique et de Morale $14(5): 627-650$.

- . 2014. Toward Principia Mathematica, 1905-08. Vol. 5 of The Collected Papers of Bertrand Russell, ed. by G. H. Moore. London and New York: Routledge.

Short, T. L. 2007. Peirce's Theory of Signs. Cambridge: Cambridge University Press.

Soames, S. 2003. The Dawn of Analysis. Vol. 1 of Philosophical Analysis in the Twentieth Century. Princeton: Princeton University Press.

- .2014. The Founding Giants. Vol. 1 of The Analytic Tradition in Philosophy. Princeton: Princeton University Press.

Tarskiy, A. [Tarski, A.] 1998. "Semanticheskaya kontseptsiya istiny i osnovaniya semantiki [The Semantic Conception of Truth and the Foundation of Semantics]" [in Russian]. In Analiticheskaya filosofiya: stanovleniya i razvitiye [Analytic Philosophy: Reader], ed. by A. F. Gryaznov, trans. from the English by A. L. Nikiforov, 90-129. Moskva [Moscow]: Dom intellektual'noy knigi / Progress-Traditsiya.

Thompson, M. H. 1949. "The Logical Paradoxes and Peirce's Semiotic." The Journal of Philosophy 46 (17): 513-536.

Yablo, S. 1993. "Paradox without Self-Reference." Analysis 53 (4): 251-252.

Yermolenko, D. V. 1965. Sovremennaya burzhuaznaya filosofiya $v$ SShA [The Contemporary Bourgeois Philosophy in the USA] [in Russian]. Moskva [Moscow]: Mezhdunarodnyye otnosheniya.

Yum, D. [Hume, D.] 2009. Traktat o chelovecheskoy prirode. Kniga 1. O poznanii [A Treatise of Human Nature. Book 1. On the Understanding] [in Russian]. Trans. from the English by S. I. Tsereteli. Moskva [Moscow]: Kanon+. 